DURÃO, Rosana; Orega, Isabel; Simonot, Catherine - "O Rato que Comeu a Língua". - A rádio na salade

Aula. Para lá da tarefa: implicar os estudantes na aprendizagem de línguas estrangeiras no ensino superior. Porto: FLUP, 2019, pp. 135-148 DOI: https://doi.org/10.21747/9789898969217/paraa7

\title{
"O Rato que Comeu a Língua" - A rádio na sala de aula
}

\author{
Rosana Durão \\ Escola Superior de Educação e Comunicação, Universidade do Algarve \\ rosfer@ualg.pt \\ Isabel Orega \\ Escola Superior de Educação e Comunicação, Universidade do Algarve \\ miorega@ualg.pt

\section{Catherine Simonot} \\ Escola Superior de Educação e Comunicação, Universidade do Algarve \\ csimonot@ualg.pt
}

\section{Resumo}

De acordo com a abordagem ao ensino de línguas baseado em tarefas (Nunan, 1989, 1999; Richards \& Rodgers, 2014; Castro, 2017), o trabalho na aula de línguas deverá ser planificado tendo em conta tarefas o mais próximas possível da comunicação em contexto real e não apenas tarefas pedagógicas, frequentemente demasiado centradas em aspetos formais da língua. Esta abordagem, promovida pelo projeto europeu PETALL, desenvolvido de 2013 a 2016, na ESEC da UALG, proporciona o enquadramento teórico para o trabalho de produção de conteúdos para o programa de rádio "O Rato que comeu a Língua». Trata-se de uma iniciativa do departamento de Línguas, Literaturas e Culturas, no âmbito do ensino do Inglês, francês, espanhol e também do português. Este trabalho é transversal a vários cursos, com diversas valências, envolvendo alunos e professores das opções de língua oferecidas. O objetivo principal é a criação de conteúdos à volta da temática das línguas e culturas para um programa semanal na rádio universitária RUA, com a duração de 5 minutos. Pretende dar a conhecer curiosidades, histórias, situações, falar sobre o Algarve e a universidade, nomeadamente as experiências dos alunos Erasmus (incoming e outgoing). Embora esta iniciativa ainda esteja em fase inicial, tem-se apresentado como uma abordagem motivadora que resulta numa aprendizagem ativa. (QECR, 2001).

Palavras-chave: ensino de línguas baseado em tarefas, motivação, ensino para fins específicos, inovação no ensino superior. 
DURÃO, Rosana; Orega, Isabel; Simonot, Catherine - "O Rato que Comeu a Língua". - A rádio na salade Aula. Para lá da tarefa: implicar os estudantes na aprendizagem de línguas estrangeiras no ensino superior. Porto: FLUP, 2019, pp. 135-148 DOI: https://doi.org/10.21747/9789898969217/paraa7

\begin{abstract}
According to the task-based approach to language teaching (Nunan, 1989, Richards \& Rodgers, 2014; Castro, 2017), language class work should be planned in the light of tasks that as close as possible to real communication and not just pedagogical tasks, which are often too focused on the formal aspects of language. This approach, promoted by the European project PETALL, developed from 2013 to 2016, at ESEC, UALG, provides the theoretical framework for the content production of the radio program «The Mouse who ate its tongue». It is an initiative of the Languages, Literatures and Cultures Department, within the scope of teaching English, French, Spanish and also Portuguese. This work is transversal to several degrees, with different values, involving students and teachers of the offered language options. The main objective is to create content around the theme of languages and cultures for a weekly program on RUA university radio, with a duration of 5 minutes, to talk about facts, stories, situations, the Algarve and the University, including the experiences of Erasmus students (incoming and outgoing). Although this initiative is still in an early stage, it has emerged as a motivational approach that results in active learning. (QECR, 2001).
\end{abstract}

Keywords: task-based language teaching, motivation, teaching for specific purposes, innovation in higher education

\title{
1 - Introdução
}

A atividade apresentada neste artigo foi pensada e elaborada no âmbito das unidades curriculares de língua, na ESEC da UALG. Foi uma estratégia de política linguística da direção da escola e das direções de cursos, há vários anos, a de oferecer três línguas de opção a todos os cursos de 1. ciclo, licenciaturas. A opção de uma língua é obrigatória, ou seja, os alunos devem escolher uma das línguas estrangeiras como parte da formação troncal, ou noutros casos a opção de língua é oferecida num conjunto de outras opções. Num dos cursos, em cujo plano de estudos a escolha de uma língua é obrigatória em dois semestres consecutivos, existem várias combinações de pares de línguas possíveis (francês num semestre e espanhol ou inglês no outro semestre, por exemplo). Noutros cursos, existem duas opções de língua não obrigatórias, mas em anos diferentes, o que permite também uma combinação de línguas. Em termos de contacto docente/discente, existe uma variação que pode rondar um mínimo de 37,5 e 
DURÃO, Rosana; Orega, Isabel; Simonot, Catherine - "O Rato que Comeu a Língua". - A rádio na salade Aula. Para lá da tarefa: implicar os estudantes na aprendizagem de línguas estrangeiras no ensino superior. Porto: FLUP, 2019, pp. 135-148 DOI: https://doi.org/10.21747/9789898969217/paraa7

um máximo de 60 horas de contacto. A língua portuguesa também é oferecida em vários cursos, nuns como unidade curricular obrigatória e noutros como opção.

Neste contexto, em que todo o corpo discente é incentivado a aprender línguas, a construção de atividades transversais aos cursos é possível e recomendável, sendo também uma aspiração de longa data a articulação de conteúdos entre as várias línguas oferecidas.

Por outro lado, são incentivadas pela própria instituição as atividades ditas de extensão no âmbito das unidades curriculares. Funcionam como uma forma de intervenção na comunidade e são uma componente muito valorizada.

É neste contexto que surge a criação do programa de rádio que aqui se apresenta, com o título «O Rato que Comeu a Língua» («El Ratón que se comió la lengua» «The mouse who ate his tongue», «La souris qui a mangé sa langue»).

\section{2 - A Abordagem de Ensino de Línguas baseado em Tarefas}

O Quadro Europeu Comum de Referência para as Línguas (QECR, 2001) propõe uma abordagem ao ensino e aprendizagem de línguas orientada para a ação. Quem aprende uma língua é visto essencialmente como um utilizador dessa língua, que tem de cumprir várias tarefas em contextos diversificados.

De acordo com Richards \& Rodgers (2014), o ensino de línguas baseado em tarefas (TBLT, em inglês) define-se mais como uma abordagem do que como um método e caracteriza-se pelo uso de tarefas como unidade central na planificação e implementação dos planos de unidade e aula. Esta abordagem é considerada um desenvolvimento lógico da abordagem comunicativa, uma abordagem inovadora, que revolucionou o ensino de línguas nos anos 80 do século vinte, dado que partilham princípios semelhantes. Richards \& Rodgers (2014, p. 174) referem que: "Activities that involve real communication are essential for language learning. Activities in which language is used for carrying out meaningful tasks promote learning. Language that is meaningful to the learner supports the learning process."

Neste contexto, as «meaningful tasks» implicam um desempenhar de tarefas que se adequam ao contexto e que têm um significado para o utilizador da língua, representando, assim, um enfoque na comunicação real.

Como a noção de «task» ou tarefa é central nesta abordagem, importa considerar como vários autores definem este conceito. Nunan (1989, p. 10) apresenta a sua definição de tarefa, já considerada clássica, do seguinte modo: 
DURÃO, Rosana; Orega, Isabel; Simonot, Catherine - "O Rato que Comeu a Língua". - A rádio na salade Aula. Para lá da tarefa: implicar os estudantes na aprendizagem de línguas estrangeiras no ensino superior. Porto: FLUP, 2019, pp. 135-148 DOI: https://doi.org/10.21747/9789898969217/paraa7

[...] a piece of classroom work which involves learners in comprehending, manipulating, producing or interacting in the target language while their attention is focused on mobilizing their grammatical knowledge in order to express meaning, and in which the intention is to convey meaning rather than to manipulate form. The task should also have a sense of completeness, being able to stand alone as a communicative act in its own right with a beginning, a middle and an end.

Nunan (1989, citado em Nunan 1999) também distingue tarefas reais e tarefas pedagógicas. A maioria das tarefas numa aula de língua é pedagógica; por exemplo, "listening to a weather forecast and deciding what to wear; responding to a party invitation; completing a banking application form; describing a photograph of one's family" (pp. 24-25).

Richards e Rodgers (2014, p.175) ainda referem que:

a task is an activity or goal that is carried out using language, such as finding the solution to a puzzle, reading a map and giving directions, making a telephone call, writing a letter or reading a set of instructions and assembling a toy.

Castro (2017, pp. 30-31) de acordo com a definição de tarefa de Ellis (2003) como workplan explica que "uma tarefa é, um plano de uma atividade, mas que não determina as estruturas linguísticas necessárias para atingir o resultado solicitado, embora crie um espaço semântico e promova a necessidade de certos processos cognitivos que se encontram ligados a determinadas opções linguísticas."

Van den Branden (2006) citado em Richards e Rodgers (2014) define vários papéis que os professores têm de desempenhar numa abordagem de ensino de línguas baseada em tarefas, tais como: motivar os alunos e apoiá-los ao longo das várias fases de desenvolvimento de uma tarefa; organizar o trabalho dando instruções claras e orientando a formação de grupos; fornecer os materiais necessários ou dar informações sobre como os obter. Nesta abordagem, o professor tem um papel de orientador do trabalho, enquanto se espera que os alunos estejam mais em destaque e sejam ativos na preparação e desenvolvimento das tarefas.

O recurso a tarefas nas aulas de língua estrangeira traz uma série de vantagens que estão associadas a este tipo de abordagem do ponto de vista pedagógico e comunicativo. De facto, uma vez que as tarefas são geralmente centradas no aluno e envolvem procedimentos de resolução de problemas ou desenvolvimento de produtos, 
DURÃO, Rosana; Orega, Isabel; Simonot, Catherine - "O Rato que Comeu a Língua". - A rádio na salade

Aula. Para lá da tarefa: implicar os estudantes na aprendizagem de línguas estrangeiras no ensino superior. Porto: FLUP, 2019, pp. 135-148 DOI: https://doi.org/10.21747/9789898969217/paraa7

o processo de aprendizagem adquire uma dinâmica distinta das abordagens mais tradicionais baseadas, em grande medida, no uso do manual escolar e no trabalho em torno do texto escrito e dos exercícios de língua. Efetivamente, a tarefa coloca, normalmente, os alunos perante desafios práticos, facilita a interação e torna-os responsáveis pelos resultados do processo de comunicação. É, por isso, também, um fator de motivação que faz com que os alunos adiram às propostas de trabalho e se empenhem no seu desenvolvimento.

\section{1 - O Projeto PETALL}

De 2013 a 2016, a Escola Superior de Educação e Comunicação representando a Universidade do Algarve coordenou um projeto Europeu, PETALL, que é o acrónimo para Pan-European Task-based Activities for Language Learning. O projeto foi financiado pela Comissão Europeia, através do Programa de Aprendizagem ao Longo da Vida (Lifelong Learning Programme), tinha como objetivo geral incentivar a aprendizagem de línguas estrangeiras baseada em tarefas através da utilização das TIC na sala de aula, fornecendo exemplos de boas práticas em consonância com as recomendações do Quadro Europeu Comum de Referência para as Línguas (QECR). Coordenado pela Universidade do Algarve, este projeto envolveu um total de dez países (Portugal, Espanha, Itália, Holanda, Reino Unido, Alemanha, Sérvia, Hungria, Grécia e Turquia), cada um deles representado por um tandem constituído por uma instituição de ensino superior ligada à formação de professores e uma escola do ensino básico ou secundário.

Em termos mais específicos, o projeto visava operar uma mudança de foco na aula de línguas, procurando levar os professores a um questionamento crítico das metodologias seguidas, a inovarem as suas práticas e a evitarem a dependência excessiva de abordagens mais tradicionais ou de práticas demasiado rotineiras. Por outro lado, o projeto também procurou sensibilizar os professores para a necessidade de se apostar cada vez mais no desenvolvimento da competência comunicativa dos jovens. Deste modo, garante-se que estes, mais do que terem de provar que são possuidores de conhecimentos linguísticos ou gramaticais a serem testados em momentos de avaliação formal, são efetivamente capazes de usar e usufruir da língua em situações reais. Para tal, podem utilizar um amplo leque de propósitos, tanto de natureza social, como cultural ou profissional.

As tarefas visam ajudar cada aluno a desenvolver não apenas as competências linguísticas, mas também a sua capacidade de aprendizagem, de adaptação e de 
DURÃO, Rosana; Orega, Isabel; Simonot, Catherine - "O Rato que Comeu a Língua". - A rádio na salade Aula. Para lá da tarefa: implicar os estudantes na aprendizagem de línguas estrangeiras no ensino superior. Porto: FLUP, 2019, pp. 135-148 DOI: https://doi.org/10.21747/9789898969217/paraa7

intervenção, aos mais diversos níveis, incluindo o tecnológico. A interação dialógica com o outro, que se encontra subjacente a um número significativo de tarefas, promove não apenas o relacionamento interpessoal, como também a capacidade de inquirição, o pensamento crítico, a criatividade, o ensejo de comunicar, o trabalho colaborativo para a resolução de problemas e tomada de decisão, e, ainda, o sentido de liderança.

Além disso, o projeto PETALL teve a virtude de pôr os próprios professores em diálogo, influenciando as abordagens pedagógicas uns dos outros e levando a que se estabelecessem contactos com outras áreas do currículo, influindo nos projetos de escola e dinamizando o diálogo entre instituições de países diferentes.

Ao nível da Escola Superior de Educação e Comunicação, considera-se que o projeto PETALL inspirou o trabalho dos vários docentes de língua, que repensaram as suas práticas, porque participaram ativamente no projeto, porque tiveram conhecimento através do Departamento de Línguas, Literaturas e Culturas ou porque, mais tarde, seguiram esta abordagem nos seus próprios trabalhos de investigação. O programa de rádio também tem por base esta abordagem ao ensino de línguas e pode-se, por isso, dizer que se trata de uma experiência de disseminação do mesmo.

\section{3 - Política linguística e de extensão da instituição}

O ensino politécnico tem tido desde sempre uma forte ligação à comunidade e ao mercado de trabalho. Nesta perspetiva, assiste-se ao reforço por parte da própria instituição do desenvolvimento de atividades de extensão, já que nos últimos anos inseriu formalmente a componente «extensão» na grelha da avaliação de desempenho docente.

Assim, o programa de rádio «O Rato que Comeu a Língua» surge num contexto que assenta em três princípios:

- o desenvolvimento de atividades de extensão;

- o empenho do corpo docente do departamento de línguas numa vontade comum de atender à necessidade de implementar novos ambientes de aprendizagem e novas formas de motivar os alunos;

- a necessidade pedagógica de inovação e de luta contra a desistência de uma parte do corpo discente no ensino superior. 
DURÃO, Rosana; Orega, Isabel; Simonot, Catherine - "O Rato que Comeu a Língua". - A rádio na salade

Aula. Para lá da tarefa: implicar os estudantes na aprendizagem de línguas estrangeiras no ensino superior. Porto: FLUP, 2019, pp. 135-148 DOI: https://doi.org/10.21747/9789898969217/paraa7

\section{1 - $O$ contexto de ensino-aprendizagem em que se insere o programa}

\section{de Rádio}

Outro aspeto que facilita a construção do projeto é o contexto de ensinoaprendizagem. Neste contexto, o acesso ao saber é complexo; traduz-se num modelo de mediação entre saber e discente, composto por recursos humanos, tecnologias, gestão do tempo e recursos linguísticos e em que se vão articular diversas metodologias de ensino e aprendizagem e de avaliações. A conceção dessas organizações técnicas e pedagógicas depende dos participantes, podendo, por conseguinte, variar muito de uma unidade curricular para outra, de docente para docente. Em cada unidade curricular, são definidas tipologia de horas de trabalho dos alunos, metodologia de ensino, de aprendizagem e de avaliação. Estamos num contexto onde existe uma flexibilidade na organização do acesso ao saber.

Podemos afirmar que, na nossa escola, no departamento de línguas, apesar de existirem unidades curriculares diferenciadas, os docentes das várias línguas (português, francês, inglês e espanhol) afastaram as suas metodologias das metodologias tradicionais. Comparado com modelos tradicionais, em que a relação pedagógica se baseia na imposição de um saber, de informações e conceitos, pelo professor, o contexto de ensino de línguas na nossa escola traz ambientes mais sofisticados, em que alunas e alunos podem fazer a experiência do saber - a expressão é de Peeters e Charlier (1999) -, manusear conceitos e ideias por iniciativa própria, tendo oportunidade de desenvolver a sua autorregulação, num contexto de maior autonomia na aprendizagem, entendida como objetivo, mas, também, como meio de aprendizagem. Nas licenciaturas oferecidas, a autonomia é exercitada no trabalho dito independente, com um número de horas três vezes superior ao tempo presencial o que proporciona uma vantagem para o desenvolvimento de tarefas e projetos.

No modelo de acesso ao saber referido acima, a avaliação tem dimensão variável, e a autonomia é posta à prova em muitos casos, por exemplo na preparação de trabalhos de grupo ou individuais e na elaboração de portefólios. Um discente terá maior êxito nos seus estudos se tiver uma atitude ativa e autorregulada na sua aprendizagem. A autonomia é um parâmetro importante para o sucesso nos estudos.

A complexidade do contexto de ensino-aprendizagem exige também que os docentes deixem espaço para que assim seja. Os docentes não podem dar uma aula expositiva e esperar que os discentes tenham uma atitude ativa. A aprendizagem acontece se os discentes assim o querem, numa participação ativa, compreendida como vontade de integração dos saberes por estratégias escolhidas de maneira consciente. É promovida 
DURÃO, Rosana; Orega, Isabel; Simonot, Catherine - "O Rato que Comeu a Língua". - A rádio na salade Aula. Para lá da tarefa: implicar os estudantes na aprendizagem de línguas estrangeiras no ensino superior. Porto: FLUP, 2019, pp. 135-148 DOI: https://doi.org/10.21747/9789898969217/paraa7

uma abordagem crítica e criativa, deixando de lado a transmissão simples de saberes, dando valor à necessária autonomia dos alunos.

Podemos concluir que, neste contexto, a responsabilidade da aprendizagem é recentrada no aluno inserido numa rede de aprendizagem.

\section{2 - O programa de rádio como fator de motivação}

Os psicólogos e os sócio-cognitivistas já mostraram há muito que a aprendizagem decorre de fatores de motivação. Para Fenouillet (2003), a motivação entende-se como uma força intra-individual, que pode ter inúmeras formas de se gerar e manifestar, através de fatores internos, mas também externos. Parece-nos claro, desde já, que os fatores externos só podem agir como motivadores pela sua transformação em fatores internos porque nós agimos por impulso interno. Para Damásio (2017), a aprendizagem, que os teóricos da aquisição e da aprendizagem das línguas definiram como consciente há várias décadas (Krashen, 1983), só funciona se algo interno for ativado. Em todo o caso, para Fenouillet, ainda, essa força é que origina uma direção, um empenhamento, a persistência e a intensidade na ação e no comportamento. A determinação é que permite a definição de objetivos pessoais e de autorregulação, logo, uma condição propícia ao sucesso. A motivação dos alunos e o seu sucesso académico não podem ser tratados em separado na definição de objetivos e competências para as unidades curriculares.

Sabemos que a motivação na aprendizagem em contexto obrigatório é variável. A rigidez dos quadros institucionais faz com que os objetivos traçados pelos alunos sejam, demasiadas vezes, condicionados pelo resultado quantitativo e pelas metas impostas pelos programas. Mas o sentimento de competência é altamente motivador para a aprendizagem. As escolhas dos alunos dão sentido à aprendizagem. A tarefa funciona como trabalho de consciencialização dos elementos de aprendizagem necessários para chegar ao resultado final, dá um sentido. O resultado da tarefa, que se vai inserir num projeto mais vasto, funciona, igualmente, como fator de motivação. Finalmente, a fórmula de avaliação da tarefa não prejudicou esta motivação.

\section{4 - 0 «Rato que Comeu a Língua»}

"O Rato que Comeu a Língua» teve como promotores um conjunto de alunos do Curso das Ciências da Comunicação da ESEC da Universidade do Algarve (2017/2018). Foi no âmbito de uma tarefa de uma unidade curricular de língua estrangeira, que aliava um ponto específico da matéria programada aos meios de comunicação, que surgiu a 
DURÃO, Rosana; Orega, Isabel; Simonot, Catherine - "O Rato que Comeu a Língua". - A rádio na salade Aula. Para lá da tarefa: implicar os estudantes na aprendizagem de línguas estrangeiras no ensino superior. Porto: FLUP, 2019, pp. 135-148 DOI: https://doi.org/10.21747/9789898969217/paraa7

ideia de que seria interessante a criação de um programa de rádio cujos conteúdos fossem elaborados pelos alunos. Esta iniciativa começa então a ganhar forma nesse mesmo ano, envolvendo as aulas de Espanhol, de Francês e de Inglês, tendo em consideração que as unidades curriculares de línguas, nos respetivos programas, enfocam as áreas específicas dos respetivos cursos de licenciatura e que são essas as línguas estrangeiras oferecidas pelo departamento. A língua portuguesa foi integrada posteriormente, por via da unidade curricular de Técnicas de Expressão Verbal.

Assim, após reunião com as docentes das respetivas línguas para apreciação da ideia dos alunos, ficou acordado que, no ano letivo seguinte, esta tarefa seria incluída no programa de cada uma das línguas, sob a forma de trabalho final, determinando-se a criação de conteúdos para um programa de rádio em que se destacam as línguas, curiosidades sobre as mesmas e a multiculturalidade característica dos alunos da UALG.

O Algarve caracteriza-se por ser uma região turística, de imigração e de multiculturalidade e a comunidade académica, no seu conjunto, reflete essa característica na forma como se movimenta e nos interesses que mostra ter.

A ideia surgiu, portanto, num contexto em que, até ao momento, não tinha havido espaço para a promoção de línguas e culturas num ambiente de tanta diversidade linguística e cultural como é o do Algarve. Verificamos também que esta diversidade, como já referimos anteriormente, se espelha na comunidade académica da Universidade do Algarve, que acolhe alunos e docentes da região, do país e cada vez mais alunos internacionais. Aproveitou-se também o facto de a escola estar ligada à RUA FM (Rádio Universitária do Algarve), que será o canal através do qual será transmitido o programa de rádio.

A intenção é aproveitar todas as valências, dentro e fora da universidade, e estruturar conteúdos que relatem a realidade acima referida, de uma forma divertida, interessante e cativante para o público-alvo da rádio universitária.

As principais linhas orientadoras para a criação de conteúdos são dar a conhecer curiosidades, histórias, situações, o Algarve e a universidade (alunos Erasmus incoming e outgoing), sendo que o seu formato será o de um programa de rádio semanal de curta duração, de três a cinco minutos.

O esqueleto deste programa de rádio será experimentado na sala de rádio da ESEC, em setembro de 2019, e pretende-se que seja um trabalho de longo prazo, que inclua sempre a participação dos alunos do curso de Ciências da Comunicação do primeiro ano, com os trabalhos elaborados para cada uma das UC de língua e com a colaboração 
DURÃO, Rosana; Orega, Isabel; Simonot, Catherine - "O Rato que Comeu a Língua". - A rádio na salade Aula. Para lá da tarefa: implicar os estudantes na aprendizagem de línguas estrangeiras no ensino superior. Porto: FLUP, 2019, pp. 135-148 DOI: https://doi.org/10.21747/9789898969217/paraa7

dos alunos do ano anterior. Os alunos que, neste momento, estão no segundo ano e foram os mentores desta ideia terão a responsabilidade de «chefiar» os do primeiro ano, num núcleo editorial que está a ser criado e que coordenará os trabalhos de seleção e elaboração dos conteúdos que foram produzidos pelos seus colegas.

Tudo isto acontece no primeiro semestre do primeiro ano, querendo dizer que, no segundo semestre desse mesmo ano letivo, o núcleo já terá produção suficiente para avançar. Trata-se de um trabalho de colaboração entre alunos de vários anos, uma espécie de «clube editorial» em que qualquer aluno poderá participar e envolver-se na dinâmica.

Esta tarefa mostrou-se até agora como motivadora para os alunos já que veem que os seus trabalhos poderão ter um destino concretizável e que não ficarão «dentro da gaveta» do professor. Os alunos têm demonstrado um sentido de responsabilidade muito maior e têm sido muito mais criativos. Esta dinâmica tem sido importante para o desenvolvimento do conhecimento adquirido pelos alunos em outras unidades curriculares, articulando, nomeadamente, conhecimentos adquiridos na UC de estudos radiofónicos, entre outras que abordam questões editoriais. É um «hands on» que os leva a trabalhar de forma transversal, utilizando a matéria adquirida em várias UC do curso e faz com que os trabalhos ganhem visibilidade e sejam importantes para o curriculum pessoal. Para além disto, os alunos interagem mais com os colegas de outros anos, de outros cursos e com alunos Erasmus de diferentes países e culturas.

Em termos de avaliação, em cada unidade curricular de língua estrangeira, cada um dos trabalhos em grupo apresentados e preparados tem a ponderação de sensivelmente $30 \%$. Os temas são escolhidos tendo em conta a criação de conteúdos para a referida rubrica do programa de rádio e os grupos incluem um máximo de 2 elementos (3, em casos excecionais e previamente concertados). Os trabalhos são avaliados numa versão escrita, em formato de relatório, e numa apresentação oral na língua em questão, em que se descreve o material/conteúdo criado para o programa de rádio. Os alunos são avaliados em grupo pela qualidade do trabalho apresentado/criado e individualmente pela qualidade da apresentação em termos de expressão oral.

$\mathrm{Na}$ apresentação destes conteúdos, os alunos são livres de escolher o modelo/formato de apresentação: vídeo, presencial, PowerPoint, entre outros. Mas são sempre incentivados pelo professor a serem criativos e a recorrerem ao material e a vários recursos que têm à disposição na escola, como são as câmaras de filmar e o estúdio de gravação. 
DURÃO, Rosana; Orega, Isabel; Simonot, Catherine - "O Rato que Comeu a Língua". - A rádio na salade Aula. Para lá da tarefa: implicar os estudantes na aprendizagem de línguas estrangeiras no ensino superior. Porto: FLUP, 2019, pp. 135-148 DOI: https://doi.org/10.21747/9789898969217/paraa7

Posteriormente, no início do semestre seguinte, o docente de cada UC de línguas entrega uma cópia de cada trabalho ao Núcleo editorial, que reúne para escolher as ideias apresentadas e faz uma seleção das que irá utilizar, podendo algumas delas ser melhoradas ou adaptadas.

As classificações que os alunos obtiveram em cada UC de língua não influenciam a escolha, já que os mesmos foram avaliados seguindo os critérios previamente estabelecidos para a apresentação de cada trabalho. Por exemplo, um trabalho com uma nota baixa na UC não fica descartado da seleção, assim como um trabalho com uma nota alta poderá ter de ser adaptado. O que conta para o núcleo é a ideia, o tema escolhido, que poderá ser melhorado ou adaptado, e não exclusivamente a qualidade em termos de língua.

No desenrolar desta tarefa, surgiu também do entusiasmo dos alunos a necessidade de criar/adaptar uma imagem. Foi-nos apresentada uma proposta com a imagem de um rato empunhando um megafone, para representar o programa. A figura do rato surge como símbolo de alguém astuto, que se adapta a qualquer realidade e contexto. A questão do nome é uma alusão ao programa da rádio comercial - O homem que mordeu o cão - cujos conteúdos são baseados em curiosidades, non-sense que se vê à volta do mundo, criado e retratado pela figura do comediante/escritor/apresentador Nuno Markl. Foi o mote de inspiração para aquilo que foi a ideia inicial de criar algo descontraído, divertido, curioso, mas que, ao mesmo tempo, servisse como mostra do que os alunos conseguem efetivamente fazer ou espelhar, no seu dia-a-dia de investigação, nas tarefas de aula, mas que tivesse um final útil e materializado.

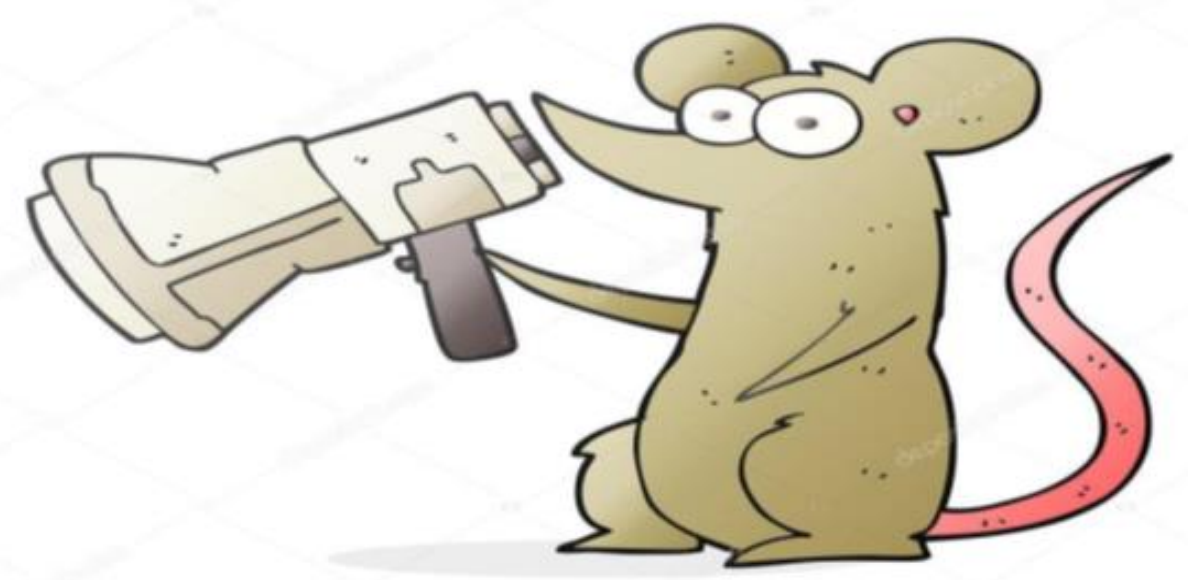

Imagem 1. Imagem do Rato que Comeu a Língua 
DURÃO, Rosana; Orega, Isabel; Simonot, Catherine - "O Rato que Comeu a Língua". - A rádio na salade Aula. Para lá da tarefa: implicar os estudantes na aprendizagem de línguas estrangeiras no ensino superior. Porto: FLUP, 2019, pp. 135-148 DOI: https://doi.org/10.21747/9789898969217/paraa7

No caso das docentes convidadas a participar, docentes das UC de Francês, de Inglês e de Português, surgiu imediatamente uma reação positiva que as levou a querer participar por ser algo inovador, mas também por serem docentes do mesmo departamento. Esta colaboração implicou uma maior articulação dos conteúdos dos programas das diferentes línguas, tendo em conta que estes são da autoria individual de cada docente.

No entanto, foi sempre hábito destas docentes inserir no âmbito das suas aulas atividades de extensão nas UC de línguas da ESEC, em particular no Curso de Ciências da Comunicação. Exemplos disto são: criação de notícias que funcionaram como relatórios de eventos realizados e que foram efetivamente publicadas em e-book, ou as tarefas que implicam a realização de visitas guiadas nas respetivas línguas, no âmbito do evento Algarve Design Meeting, que já vai na sua 9.ㄹ edição; um evento pivô da escola, mas também um evento de referência na área do Design a nível nacional e internacional e que tem lugar na Cidade de Faro.

Outras atividades têm envolvido concursos de língua, entrevistas, reportagens sobre figuras locais, correspondendo à dinâmica do que se pretende fazer. Resumindo, esta iniciativa é a materialização e concretização de um sentimento e de uma lógica que há muito se instalou na nossa maneira de trabalhar. Verificamos que agora se alargou à concertação com as várias línguas lecionadas e com a colaboração, e participação de alunos de vários anos e cursos, assim como de professores especialistas nas outras áreas da comunicação, tais como os dos estudos radiofónicos, conteúdos redatoriais, design, entre outros.

Tem sido tal o entusiasmo dos alunos, que já está em curso uma segunda tarefa para o segundo semestre de cada ano e que segue a mesma lógica do programa de rádio. Decidiu-se criar um «Boletim ESEC», uma espécie de boletim informativo da escola, com um espaço dedicado ao ensino da cultura e da língua. Será um boletim semestral através do qual também serão partilhadas curiosidades, histórias, situações relacionadas com as línguas acima mencionadas. A ideia é também criar uma espécie de Year Book onde se destaca tudo o que foi mais importante na vida académica desse ano letivo.

O esqueleto do boletim será implementado com a participação dos alunos das Ciências da Comunicação na sua redação e com a colaboração dos alunos de Design de Comunicação para o layout. Pretende-se ainda integrar alunos de outros cursos que frequentam as UC de Línguas e integrar também alunos de outros cursos, envolvendo 
DURÃO, Rosana; Orega, Isabel; Simonot, Catherine - "O Rato que Comeu a Língua". - A rádio na salade Aula. Para lá da tarefa: implicar os estudantes na aprendizagem de línguas estrangeiras no ensino superior. Porto: FLUP, 2019, pp. 135-148 DOI: https://doi.org/10.21747/9789898969217/paraa7

depois quase toda a comunidade académica da escola, nomeadamente, alunos de educação básica, educação social e o curso de desporto.

Tanto para o programa de rádio como para o boletim, será criado um núcleo editorial, com sede na escola, que reunirá uma vez por semana. A lógica é envolver os alunos do 1. ano que estão a trabalhar ativamente nestas tarefas, os do segundo e, eventualmente, os do terceiro, a «chefiar/orientar» os trabalhos em regime de voluntariado.

\section{5 - Conclusão}

O nosso «Rato» está ainda numa fase inicial ou experimental, visto que é o primeiro ano completo em que se desenvolve e estamos num período de consolidação do núcleo editorial. Foram já produzidos conteúdos para o programa de rádio, que ainda não foram triados nem selecionados, nas quatro línguas em questão.

O envolvimento demonstrado até agora pelos alunos e pelas docentes tem-se estendido a outros cursos com o «passa a palavra» e verifica-se, neste momento, o interesse de colegas de outros cursos a quererem de alguma forma inserir nos programas das suas UC tarefas que se possam depois enquadrar no âmbito do programa e do boletim.

Alguns alunos internacionais têm manifestado interesse em participar, nomeadamente alunos brasileiros de cursos na área do cinema e audiovisual, que propõem já a produção de uma minissérie, cuja base também são curiosidades, histórias e situações relacionadas com as línguas e culturas já referidas.

Vemos, assim, que está ideia vai ganhando forma em pouco tempo e que as ideias que vão surgindo para o compor são muitas, podendo-se dizer que esta em modo still in progress. O trabalho que está a ser desenvolvido vai-se alterando e adaptando à medida que se vai construindo, mas com uma estrutura base muito bem definida que se prende com as questões relacionadas com as línguas, a cultura associada às mesmas e a diversidade da comunidade académica.

\section{Referências bibliográficas}

Bandura, A. (1995). Exercise of Personal and Collective Efficacy in Changing Societies. In A. Bandura (Ed.), Self-efficacy in Changing Societies (1-45). Cambridge: Cambridge University Press.

Castro, C. (2017). Ensino de Línguas Baseado em Tarefas. Lisboa: Lidel. 
DURÃO, Rosana; Orega, Isabel; Simonot, Catherine - "O Rato que Comeu a Língua". - A rádio na salade Aula. Para lá da tarefa: implicar os estudantes na aprendizagem de línguas estrangeiras no ensino superior. Porto: FLUP, 2019, pp. 135-148 DOI: https://doi.org/10.21747/9789898969217/paraa7

Council of Europe (2001). Common European Framework of Reference for Languages. Cambridge: Cambridge University Press.

Damásio, A. (2017). A estranha ordem das coisas. Lisboa: Círculo de Leitores.

Descartes, R. (1637). O discurso do método, acedido em Fenouillet, F. (2003). La motivation. Paris: Dunod.

Fenouillet, F. (2003). La motivation. Paris: Dunod.

Flick, U. \& Fourez, G. (dir.) (2008). Abordagens didáticas da interdisciplinaridade. Lisboa: Instituto Piaget.

González-Lloret, M. (2016). A Practical Guide to Integrating Technology into Taskbased Language Teaching. Georgetown: Georgetown University Press.

Krashen S. D. (1983). The Natural Approach. Oxford: Pergamon Press.

Lopes, A., Orega, M. I. \& Tardão, L. (2015). 'PETALL: um projeto europeu de aprendizagem de línguas por tarefas com recurso às TIC'. In Gomes, M. J., Osório, A. J. \& Valente, L. (org.) Atas da IX Conferência Internacional de TIC na Educação Challenges 2015: Meio século de TIC na Educação. Universidade do Minho. Braga.

Nunan, D, (1989). Designing Tasks for the Communicative Classroom. Cambridge: Cambridge University Press.

Nunan, D. (1999). Second Language Teaching and Learning. Boston: Heinle \& Heinle Publishers.

Orega, M. I. \& Tardão, L. (2015). Four technology mediated tasks. A Portuguese experience. In Conference Proceedings ICT for Language Learning, 8th edition. Libreriauniversitaria.

Peeters, H. \& Charlier, P. (1999). Contribution à une théorie du dispositif. Hermès, 25. Paris: CNRS Éditions. 15-23.

Richards, J.C. \& Rodgers, T. S. (3rd. ed.), (2014). Approaches and Methods in Language Teaching. Cambridge: Cambridge University Press.

Thomas, M. \& Reinders, H. (eds.) (2010). Task-Based Language Learning and Teaching with Technology. London: Continuum. 